\title{
$\widehat{A}$ Madridge
}

madridge Journal of Internal and Emergency Medicine

\author{
Interconnecting Scientific World
}

Research Article

Open Access

\section{Low Dose Aspirin in prevention of Spontaneous Preterm Birth in Suez Canal University Hospital}

\author{
Zakia M Ibrahim ${ }^{1}$, Mariam L Mohamed ${ }^{1}$, Ahmed M Gadallah ${ }^{1}$, Eslam S Mahmoud ${ }^{1}$ and Hassan A Shora ${ }^{2 *}$ \\ ${ }^{\prime}$ Department of Obstetrics and Gynecology, Faculty of Medicine, Suez Canal University, Egypt \\ ${ }^{2}$ Department of Molecular Biology/Biochemistry, Port-Said University E Ismailia General Hospital, Egypt
}

\section{Article Info}

*Corresponding author:
Hassan A Shora
Senior Research Scientist
Head of Medicine \& Diabetes Center
Port-Said University \& Ismailia General
Hospital
Egypt
Tel: +201224020233
E-mail: hassanshora56@gmail.com

Received: October 6, 2019

Accepted: October 21, 2019

Published: October 28, 2019

Citation: Ibrahim ZM, Mohamed ML, Gadallah AM, Mahmoud ES, Shora HA. Low Dose Aspirin in prevention of Spontaneous Preterm Birth in Suez Canal University Hospital. Madridge J Intern Emerg Med. 2019; 3(2): 146-151.

doi: 10.18689/mjiem-1000133

Copyright: $\odot 2019$ The Author(s). This work is licensed under a Creative Commons Attribution 4.0 International License, which permits unrestricted use, distribution, and reproduction in any medium, provided the original work is properly cited.

Published by Madridge Publishers

\begin{abstract}
Background: Preterm birth (birth before 37 weeks of gestation) is a major problem in obstetrics and affects an estimated 15 million pregnancies worldwide annually. A history of previous preterm birth is the strongest risk factor for preterm birth, and recurrent spontaneous preterm birth affects more than 2.5 million pregnancies each year.
\end{abstract}

The Objective: To assess the efficacy of low-dose aspirin for the prevention of spontaneous preterm birth in pregnant women with high risk for preterm birth at Suez Canal university hospital. To assess the cost-effectiveness of low dose aspirin v.s placebo in the prevention of recurrent spontaneous preterm birth in a randomized clinical trial.

Methods/design: Women with a singleton pregnancy and a history of spontaneous preterm birth in a singleton pregnancy (16 to $<37$ weeks of gestation) were asked to participate in a randomized, double blinded, controlled trial. In total, 120 pregnant women, the first group was randomized to low dose aspirin ( $81 \mathrm{mg}$ once daily) plus folic acid $500 \mathrm{mcg}$, the second group took folic acid only. Study initiated from 8 to 16 weeks up to maximal 36 weeks and 6 days of gestation. The primary outcome measure was preterm birth, defined as birth at a gestational age $(G A)<37$ weeks.

Results: In total, 120 pregnant women were randomized to show a reduction in preterm birth. Comparison between the two study groups in terms of occurrence rates of spontaneous preterm labor according to treatment arm. It showed a statistically lower rate in study group when compared to control group (8.3\% versus $16.7 \%$ respectively, $p=0.043$ ). Since aspirin was found effective in preventing preterm birth, then, there was cost savings, because of the low costs of aspirin.

Conclusions: Low-dose aspirin treatment is an extremely attractive potential prophylactic agent for preterm birth, especially in low-resource settings, that deserves further attention and confirmation by future mega trials.

Keywords: Pregnancy; Spontaneous recurrent preterm birth; SPTB; Preterm birth; Preterm labour; PTB; Prevention; Reduction; Aspiri; Acetylsalicylic acid; ASA.

\section{Introduction}

Globally, about 15 million pregnancies each year end in preterm birth, i.e. before the 37 th week of gestation [1]. Preterm birth is the most important cause of perinatal morbidity and mortality worldwide. Despite the administration of progesterone to women with a previous spontaneous preterm birth, $20 \%-30 \%$ will deliver preterm again [2].

Preterm births (PTB) are a primary cause of neonatal deaths worldwide, with surviving infants at risk of serious neonatal complications and long-term disability [3]. The economic cost of PTB was estimated to be $£ 2.9$ billion for a single year in the UK 
$[4,5]$, with the psychological, social and financial costs to families no less profound $[6,7]$. A World Health Organization (WHO) priority-setting exercise identified PTB as a 'top ten' research priority to 2025 [8]. Experts continue to debate the optimal clinical care of pregnant women to prevent or manage PTB. Short- and long-term effects of diverse interventions must be set against women's individual histories and preferences.

Accumulating evidence suggests that uteroplacental ischemia plays an important role in the aetiology of spontaneous preterm birth, comparable to its role in preeclampsia. As aspirin is proven to reduce the risk of developing preeclampsia, it is hypothesized that aspirin might also be effective to prevent spontaneous preterm birth through its antithrombotic and anti-inflammatory effect. Several studies have shown promising results [9-11].

Low-dose aspirin (LDA) is attractive as a potential prophylactic agent against preterm birth, because it is inexpensive, widely available, and has a reasonable safety profile during pregnancy [12].

The effect of aspirin on spontaneous preterm labor as the primary main outcome not discussed. Almost all studies are discussing this issue as a secondary outcome. The vast majority of studies initiated treatment with aspirin after conception, however, often in the second trimester. Also, few studies, assessed preterm birth as a primary outcome, and most others targeted preeclampsia, fetal growth restriction, or both.

\section{Methodology}

This study was carried out as interventional study (Randomized controlled clinical trial) that was carried out in the Department of Obstetrics and Gynecology of the Suez Canal University Hospital from August 2017 till March 2018. Inclusion criteria included pregnant women aged (18-35) years, primi gravid \& multipara, singleton pregnancy, gestational age between 16 weeks till 36 weeks and high-risk patient for preterm: history of one or more preterm birth, preeclampsia in a previous pregnancy and history of gestational diabetes mellitus were included in the study. Exclusion criteria includes premature rupture of membranes, women diagnosed to have incompetent cervix, preeclampsia in current pregnancy, chronic medical illness (chronic HTN, pre-existing insulin-dependent diabetes mellitus (IDDM), cardiac diseases), multiple pregnancy (twins, triplet) and women known to have medical illness contraindicated to aspirin: bleeding disorders (low platelets, Von Willebrand's, hemophilia, thrombotic thrombocytopenic purpura, inadequate vitamin $\mathrm{K}$ ), women who are known to have any cardiac diseases, women who were known to have allergy against aspirin and bleeding stomach ulcers.

Simple random sampling in which a computerized random sample was taken from the study population. Sample size was 120 pregnant women, 60 for each group after addition of $10 \%$ drop-out rate.

\section{Study population}

The studies were carried on pregnant women with high risk for spontaneous preterm birth attending or referred to the outpatient clinic and were randomly assigned into one of two groups:

Control group: Pregnant women with high risk for preterm birth were treated with folic acid $5 \mathrm{mg}$ plus conventional strategies used in preterm birth (progesterone, cervical Cerclage "if needed", Tocolytics, and Steroids), with continuous follow up to 36 weeks or up to delivery whatever came first.

Interventional group: Pregnant women with high risk for preterm birth were treated with low dose aspirin ( $81 \mathrm{mg}$ daily) ]Trade name: Aspirin $81 \mathrm{mg}, 30$ chewable tab[+Folic acid 5 $\mathrm{mg}$ daily trade name Folic acid $500 \mathrm{mcg} 20$ tab[, plus conventional strategies used in preterm birth such as (administration of progesterone, cerclage "if needed" or pessary according to local protocols for prevention of preterm birth derived from national guidelines, with continuous follow up to 36 weeks or up to delivery whatever came first.

\section{Study steps}

All patients enrolled in the study were subjected to:

1. An informed written consent obtained from all patients participating in the study (Appendix).

2. Complete personal, obstetric and medical history:

- Name, age, address, occupation, duration of marriage.

- Gravidity, parity, last menstrual period (LMP), number of living children, mode and place of previous deliveries, history of previous preterm birth.

- Any general medical conditions as hypertension and diabetes mellitus, heart diseases, renal diseases or history of drug intake.

3. Complete general examination specially:

- Vital signs (blood pressure (BP), pulse, body temperature).

- Lower limb edema.

4. Obstetrics examination

- Fundal level and palpation of contractions.

- Vaginal examination in lithotomy position by sterile Cusco speculum in good illumination for (leak of amniotic fluid, uterine bleeding).

- Cervical ripening was assessed by digital examination (cervical dilatation $\&$ effacement).

5. Ultrasound to:

- Confirm gestational age and number of fetuses.

- Biophysical profile BPP (fetal breathing, fetal movement, fetal tone, amniotic fluid index).

- Ultrasound to exclude congenital anomalies.

- The cervical length was measured by trans-vaginal sonography with the woman adopting the dorsal lithotomy position with an empty bladder. When the cervical canal was visualized, the probe was withdrawn to avoid pressure, distortion and elongation of the 
cervix. A sagittal view showing the entire cervix (endocervix and vaginal cervix), with the echogenic endocervical mucosa along the length of the cervical canal, was obtained. Calipers were used to measure the distance between the notches made by the junction of the anterior and posterior cervical walls at the internal and external os. Three measurements were performed (in millimeters), and the shortest distance was noted.

6. Laboratory investigations (renal function (S. creatinine), blood glucose (RBS) and urine analysis, complete blood count (CBC mainly WBCs).

7. Follow up of two groups till delivery or 36 weeks which came first was done, pregnancy outcomes, including delivery date, $\&$ mode of delivery was assessed by postpartum phone interview and through medical record review.

8. Analysis of both groups according to outcome was done, gestational age at time of delivery, evidence of complication to fetus or mother, and the classifying patients according to age, time of delivery, preterm birth phenotype was done.

\section{How to diagnose preterm birth}

1. Uterine monitoring: Evening contraction rate of $>4-6$ per hour in weeks $<37 \mathrm{wk}$.

2. Digital examination: An effaced or dilated cervix confirms the diagnosis of spontaneous preterm labour. $(2,3,4 \mathrm{~cm}$ with $50 \%$ effacement).

\section{Ultrasound:}

- Estimation of cervical length by Transvaginal ultrasound (TVUS).

- Cervical length $<30 \mathrm{~mm}$ using TVUS had a sensitivity of $100 \%$ in predicting preterm birth.

\section{Statistical analysis}

Collected data was processed using SPSS version 22, (2016) for windows. Quantitative data was expressed as mean+standard deviation while qualitative data will be expressed as numbers and percentages. Student t-test was used to test significance of difference for quantitative variables and chi square was used as a test of significance of difference for qualitative variables. A probability value ( $p$-value) $<0.05$ was considered statistically significant.

\section{Results}

We enrolled 120 patients in this study to assess the efficacy of low-dose aspirin for the prevention of spontaneous preterm birth. The study population was categorized into two groups; group (1): control group and group (2): study group or low dose of aspirin group.

Table 1 is showing group comparison of demographic data among both groups, there is no statistically significant difference between the two groups in terms of age, BMI, terms of number of previous pregnancy losses and number of previous pregnancies resulting in live birth $(p>0.05)$.
Table 1. Group comparison of demographic data among both groups.

\begin{tabular}{|c|c|c|c|}
\hline Variable & $\begin{array}{c}\text { Control Group } \\
n=60\end{array}$ & $\begin{array}{c}\text { Study group } \\
n=60\end{array}$ & $P$ value \\
\hline Age, year $($ Mean $\pm S D)$ & $30.61 \pm 2.9$ & $28.97 \pm 5.4$ & 0.39 \\
\hline $\begin{array}{l}\text { Mean body mass index at } \\
\text { conception, } \mathrm{kg} / \mathrm{m}^{2}(\text { mean } \pm \mathrm{SD})\end{array}$ & $29.01 \pm 3.29$ & $26.87 \pm 2.1$ & 0.061 \\
\hline $\begin{array}{c}\text { Parity (live birth) } \\
-\quad \text { None }\end{array}$ & 28 (46.7\%) & 27 (45\%) & \multirow{3}{*}{0.79} \\
\hline - One & 21 (35\%) & $23(38.3 \%)$ & \\
\hline - $\quad$ Two & $11(18.3 \%)$ & $10(16.7 \%)$ & \\
\hline $\begin{array}{l}\text { Past history of pregnancy loss } \\
\text { (abortion - preterm birth) } \\
\text { - One }\end{array}$ & 42 (70\%) & 40 (66.7\%) & \multirow[t]{2}{*}{0.1} \\
\hline - Two & 18 (30\%) & 20 (33.3\%) & \\
\hline
\end{tabular}

Table 2 displays a comparison between the two study groups in terms of time from last loss prior to enrollment in current study. It showed no statistically significant difference between the two groups $(p>0.05)$ [5].

Table 2. Distribution of study population in terms of time from last loss prior to enrollment in current study (months).

\begin{tabular}{|c|c|c|c|c|}
\hline Variable & $\begin{array}{c}\text { Control Group } \\
\mathrm{N}=60\end{array}$ & $\begin{array}{c}\text { Study Group } \\
\mathrm{N}=60\end{array}$ & RR $(95 \% \mathrm{Cl})$ & $p$ valt \\
\hline $0-4$ or less month & 32 (53.3\%) & $31(51.7 \%)$ & $0.98(0.66-1.46)$ & \multirow{4}{*}{0.63} \\
\hline 4-8 or less month & $11(18.3 \%)$ & $12(20 \%)$ & $1.07(0.5-2.28)$ & \\
\hline $8-12$ or less month & 4 (6.7\%) & 5 (8.3\%) & $1.2(0.3-4.3)$ & \\
\hline More than 12 months & $13(21.7 \%)$ & $12(20 \%)$ & $0.93(0.45-1.9)$ & \\
\hline
\end{tabular}

* $P$ value significant $<0.05, \mathrm{RR}$, risk ratio; $\mathrm{Cl}$, confidence interval.

Table 3 displays a comparison between the two study groups in terms of some pregnancy events in their pregnancy history (spontaneous preterm labor, preeclampsia, ectopic, multiples, still birth, therapeutic abortion, gestational diabetes and neonatal or infant death. It showed no statistically significant difference between the two groups ( $p>0.05$ ).

Table 3. Distribution of study population in terms of Obstetric history.

\begin{tabular}{|l|c|c|c|c|}
\hline Variable & $\begin{array}{c}\text { Control Group } \\
\mathrm{N}=60\end{array}$ & $\begin{array}{c}\text { Study Group } \\
\mathrm{N}=60\end{array}$ & $\mathrm{RR}(95 \% \mathrm{Cl})$ & $\mathrm{p}$ value \\
\hline $\begin{array}{l}\text { Spontaneous preterm } \\
\text { labor (n, \%) }\end{array}$ & $10(16.67 \%)$ & $5(8.3 \%)$ & $0.54(0.19-1.49)$ & 0.6 \\
\hline Preeclampsia & $5(8.3 \%)$ & $7(11.7 \%)$ & $1.3(0.45-4.6)$ & 0.23 \\
\hline Ectopic & $1(1.7 \%)$ & $2(3.3 \%)$ & $1.96(0.13-21.1)$ & 0.12 \\
\hline Multiples & $4(6.7 \%)$ & $5(8.3 \%)$ & $1.23(0.35-4.37)$ & 0.21 \\
\hline Stillbirth & $10(16.6 \%)$ & $5(8.3 \%)$ & $0.54(0.19-1.49)$ & 0.6 \\
\hline Therapeutic abortion & $3(5 \%)$ & $2(3.33 \%)$ & $0.68(0.11-3.9)$ & 0.34 \\
\hline Gestational diabetes & $8(13.3 \%)$ & $7(11.7 \%)$ & $0.89(0.34-2.3$ & 0.14 \\
\hline Neonatal death & $1(1.7 \%)$ & $1(1.7 \%)$ & $1(0.06-15.6)$ & 1 \\
\hline
\end{tabular}

* $\mathrm{P}$ value significant $<0.05, \mathrm{RR}$, risk ratio; $\mathrm{Cl}$, confidence interval.

We didn't find statistically significant differences between the two groups when compared in terms of mean gestational age as shown in table 4.

Table 4. Comparison of mean gestational age between both groups.

\begin{tabular}{|c|c|c|c|}
\hline Variable & $\begin{array}{c}\text { Control Group } \\
\qquad N=60\end{array}$ & $\begin{array}{l}\text { Study Group } \\
\qquad N=60\end{array}$ & $p$ value \\
\hline $\begin{array}{l}\text { Mean gestational age, week } \\
\text { (range) }\end{array}$ & $35.1(33.5-36)$ & $35.7(32.5-36.5)$ & 0.12 \\
\hline $\begin{array}{cc}\text { Gestational age } \\
\bullet & 28-32 \\
\bullet & 32-37 \\
\cdot & >37\end{array}$ & $\begin{array}{c}3(5 \%) \\
7(11.7 \%) \\
50(83.3 \%)\end{array}$ & $\begin{array}{c}1(1.7 \%) \\
4(6.7 \%) \\
55(91.7 \%)\end{array}$ & 0.058 \\
\hline
\end{tabular}

${ }^{*} \mathrm{P}$ value significant $<0.05$ 
A comparison between the two study groups regarding modes of delivery. It also showed no statistically significant difference between the two groups $(p<0.05)$, RR $(95 \% \mathrm{Cl})$ were1.1 (0.38-3.16) \& $0.8(0.17-3.7)$ for vaginal \& cesarean delivery for control \& study group respectively ( ${ }^{\star} \mathrm{P}$ value significant $<0.05, \mathrm{RR}$, risk ratio; $\mathrm{Cl}$, confidence interval).

A comparison between the two study groups in terms of birth weight (2.570 VS.2.437 grams) \& mean APGAR score at one and five minutes 8 (0-9\%). It also showed no statistically significant difference between the two groups $(p<0.05)$.

Side effects of low dose aspirin administration in study group, 10 cases had nausea \& vomiting (16.6\%), 5 cases had epigastric pain (8.3\%), allergic reactions (1.6\%) $(95 \% \mathrm{Cl}, 0.41-1.03)$.

A comparison between the two study groups in terms of neonatal death was (20\%) in both groups. It showed no statistically significant difference between the two groups $(p<0.05)$ RR $(95 \% \mathrm{Cl}) 1$ (0.11-8.9).

\section{Discussion}

Preterm birth is considered one of the major causes of neonatal morbidity and mortality contributing to several chronic medical hazards. Despite considerable research and clinical efforts, the rate of preterm birth continued to rise in the United States through 2006, when the overall rate of preterm birth increased to $12.8 \%$, representing a $19 \%$ increase since 1990 [13]. Since that time, rates have stabilized, slightly decreasing to $11.5 \%$ in 2012 [14].

We enrolled 120 patients in current study. They were randomly allocated into one of the two groups (study group or control group). Each group included 60 patients.

This study aimed at improving the outcomes of pregnancy and decrease incidence rates of preterm birth throughout assessment of the efficacy of application of low-dose aspirin for the prevention of spontaneous preterm birth.

In this study, the results showed that no statistically significant difference in mean age and BMI in control group when compared to the study group. This result was similar to those reported by Silver et al. [9] who also reported no significant differences between study group and control group.

According to the distribution of current population in terms of the duration from last loss prior to enrollment in current study, both groups showed highest rate in 0-4 times of loss group (53.3\% in control group and $51.7 \%$ in study group) and lowest rate in 8-12 times group (6.7\% in control group and $8.3 \%$ in study group). Overall, the distribution of the population in terms of time from last loss prior to enrollment in current study showed no significant difference between the two groups ( $p>0.05)(R R$, risk ratio; $\mathrm{Cl}$, confidence interval $=0.98 ;(0.66-1.46)$. These findings are similar to those reported by Silver and his colleagues [9] who also didn't report significant difference between the two studies groups in terms of time elapsed since last loss ( $p>0.05$ ).

Current study showed that the number of previous pregnancies with live birth outcome was none in most population in control and study group $(46.7 \%$ and $45 \%$ respectively) with overall insignificant difference between the two groups. $70 \%$ of control group comparing with $66.7 \%$ of the study group had only one previous pregnancy loss with no significant difference between the two groups ( $P$ value $=0.1$ ). These findings are similar to the results reported by other papers that also didn't display a significant difference between study and control groups regarding this issue $(p>0.05)$ [15].

According to the obstetric history gestational diabetes was the most frequent complication associated with the pregnancy in both groups ( $13.3 \%$ in control group and $11.7 \%$ in study one). $\mathrm{RR}$, risk ratio; $\mathrm{Cl}$, confidence interval $=(0.89(0.34-2.3)$. There was no statistical difference in all diseases associated with the pregnancy which included in current study.

All the previous displayed results of current study and other studies show insignificant differences between study and control group in terms of many factors such as BMI, time passed since last pregnancy loss, frequency of previous live births and pregnancy history of medical conditions such as gestational diabetes. These comparisons are excluding the possibility of these factors to have a confounding effect on current study results.

Current study results displayed a statistically significant lower rate of spontaneous preterm labor among study group (8.3\%) compared with $16.67 \%$ in the control group. In current study only fifteen cases had premature labor that was divided as ten cases in control group and five cases in the study group. These findings agree with those reported by Silver et al. [9] who also reported significant lower rates among aspirin group $(p<0.05)$.

The comparison between the two study groups in terms of occurrence rates of spontaneous preterm labor according to treatment arm. It showed a statistically lower rate in study group when compared to control group (8.3\% versus $16.7 \%$ respectively, $\mathrm{p}=0.043)$ with a relative risk of $0.67(95 \% \mathrm{Cl}$, 0.41-1.03). These findings are consistent with findings of Silver et al. study who reported a RR of $0.71(95 \% \mathrm{Cl}, 0.42-$ 1.23) [9], as displayed in the results, the majority of preterm births occurred after 34 weeks of gestation. However, the association with decreased preterm birth also was present before 34 weeks of gestation. We didn't find a statistically significant differences between the two groups when compared in terms of mean gestational age, $(35.1 \pm 2.38$ versus $35.7 \pm 1.8, p=0.12$ ). These findings are similar to those reported by Silver et al. who reported mean age of preterm birth as (35.9 versus 35.3) respectively [9].

Furthermore, the magnitude of the association with preterm birth was clinically important. It is uncertain whether the association is the result of an increased benefit from treatment initiated before conception, very early in pregnancy, or both.

In contrast, there was no trend toward a decrease in medically indicated preterm births. Moreover, aspirin was not associated with preeclampsia or gestational hypertension, the most common reason identified for medically indicated preterm delivery. This is divergent to most but not all other 
studies [12]. It is unclear whether the lack of benefit with regard to preeclampsia prophylaxis was the result of insufficient power or the result of the use of preconception treatment. It is also unclear why the association was more pronounced in women with only one early recent pregnancy loss (the only group in which the reduction in preterm birth was statistically significant). Interestingly, in the previous report of this trial, low-dose aspirin had a more favorable association in this subset of women also with regard to live births, likely as a result of an effect on fecundity rather than prevention of pregnancy loss. Women in the expanded strata often had recurrent pregnancy loss, perhaps comprising a different population.

There is strong biological plausibility that aspirin may decrease the risk for preterm birth. Cyclooxygenase inhibition can decrease prostaglandin formation, which is known to play a role in normal and abnormal labor [16].

Also, numerous other inflammatory mediators that contribute to preterm labor may be inhibited by a spirin [16]. Indeed, cyclooxygenase inhibitors are used as to colytics [17] and regular-dose aspirin is associated with a delay in the onset of labor [18]. Low-dose aspirin also has the potential to decrease the risk for medically indicated preterm births by lowering the chances of developing preeclampsia or fetal growth restriction, although the present data do not lend support to this mechanism [12].

According to gestational diabetes 8 cases (13.3\%) in the control group vs. 7 cases (11.7\%) in the study group which was comparable with what Silver et al. study reported that $10 \%$ of the study group and $12.4 \%$ of the placebo group who had gestational diabetes [9]. The difference between the mode of delivery between the two treatment arms in the preterm labor women showed no statistical significance $(P$ value $=0.097$ ). Most of the preterm labor cases had vaginal delivery $(70 \%$ of the control group and $60 \%$ of the study group) $\mathrm{RR}$, risk ratio; $\mathrm{Cl}$, confidence interval (0.8; (0.17-3.7)). Silver et al. [9] study showed about $60 \%$ of the preterm labor cases of the study group and about $68 \%$ of the control group had normal delivery. This result showed insignificant difference between the two treatment arms.

The one- and five-minute preterm labor outcome showed insignificant difference between the two study groups ( $P$ value $=0.18$ ) according to Apgar score. In contrast with Silver et al. [9] study which reported the same insignificant difference between the treatment arm groups. Furthermore, in a recently published meta-analysis and metaregression study of forty randomized clinically controlled trials of using low-dose aspirin impacts on perinatal outcomes that involved 34,807 participants. It was demonstrated that low-dose aspirin when commenced $\leq 16$ weeks gestation was significantly associated with reduced risk of perinatal death in addition to reduction in Apgar score $<7$ and periventricular hemorrhage. The metaregression analysis confirmed the effects of low-dose aspirin on perinatal death when started early at $\leq 16$ weeks gestation independent of pre-eclampsia and pre-term birth [16].
Neonatal death results in current study showed the same percentage (20\%) in the two treatment arms. Silver et al. [9] study reported insignificant difference between the two groups according to the neonatal death [17]. The main strength of current study is it's one of few studies in the literature discussing the effect of aspirin on spontaneous preterm labor as the primary main outcome. Almost all studies present in the current literature are discussing this issue as a secondary outcome. The vast majority of studies initiated treatment with aspirin after conception, however, often in the second trimester. Also, no study, assessed preterm birth as a primary outcome, and most others targeted preeclampsia, fetal growth restriction, or both.

\section{Conclusion}

Even a small reduction in preterm birth would have tremendous medical, social, and financial benefits given the wide availability, low cost, relative safety, stability, and ease of administration of low-dose aspirin.

Low dose aspirin administration has statistically significant effect on reduction of occurrence of preterm birth in study vs. control group.

Low-dose aspirin treatment is an extremely attractive potential prophylactic agent for preterm birth, especially in low-resource settings, that deserves further attention.

\section{Recommendations}

We recommend the use of low dose aspirin for prevention of spontaneous preterm birth especially for high risk women for preterm birth. Further studies are needed on larger sample size to assess the potential benefits of low dose aspirin for reduction of spontaneous preterm birth.

\section{References}

1. World Health Organization. Preterm Birth. 2018.

2. Jarde A, Lutsiv O, Beyene J, McDonald SD. Vaginal progesterone, oral progesterone, 17-OHPC,cerclage, and pessary for preventing preterm birth in at-risk singleton pregnancies:an updated systematic review and network meta-analysis. BJOG. 2019; 126(5): 556-567. doi: 10.1111/1471-0528.15566

3. Blencowe $H$, Cousens $S$, Chou $D$, et al. Born too soon: the global epidemiology of 15 million pretermbirths. Reprod Health. 2013; 10: S2. doi: 10.1186/1742-4755-10-S1-S2

4. Mangham L, Petrou S, Doyle LW, Draper E, Marlow N. The cost of preterm birth throughout childhood in England and Wales. Pediatrics. 2009; 123(2): e312-e327. doi: 10.1542/peds.2008-1827

5. Hodek JM, von der Schulenburg JM, Mittendorf T. Measuring economic consequences of preterm birth - Methodological recommendations for the evaluation of personal burden on children and their caregivers. Health Econ Rev. 2011; 1(1): 6. doi: 10.1186/2191-1991-1-6

6. Carson C, Redshaw M, Gray R, Quigley M. Risk of psychological distress in parents of preterm children in the first year: evidence from the UK Millennium Cohort Study. BMJ Open 2015; 5(12): e007942. doi: 10.1136/ bmjopen-2015-007942

7. Vigod SN, Villegas $L$, Dennis $C L$, Ross LE. Prevalence and risk factors for postpartum depression among women with preterm and low-birthweight infants: a systematic review. BJOG. 2010; 117(5): 540-550. doi 10.1111/j.1471-0528.2009.02493.x 
8. Yoshida S, Martines J, Lawn JE, et al. Setting research priorities to improve global newborn health and prevent stillbirths by 2025. J Glob Health. 2016; 6(1): 010508. doi: 10.7189/jogh.06.010508

9. Silver RM, Ahrens K, Wong LF, et al. Low-dose aspirin and preterm birth: a randomized controlled trial. Obstet Gynecol. 2015; 125(4): 876-884. doi: 10.1097/AOG.0000000000000736

10. Van Vliet EO, Askie LA, Mol BW, et al. Antiplatelet Agents and the Prevention of Spontaneous Preterm Birth: A Systematic Review and Metaanalysis. Obstet Gynecol. 2017; 129(2): 327-336. doi: 10.1097/ AOG.0000000000001848

11. Andrikopoulou M, Purisch SE, Handal-Orefice R, Gyamfi-Bannerman C. Low-dose aspirin is associated with reduced spontaneous preterm birth in nulliparous women. Am J Obstet Gynecol. 2018; 219(4): 399.e1-399.e6. doi: 10.1016/j.ajog.2018.06.011

12. Duley L, Henderson-Smart DJ, Meher S, King JF. Antiplatelet agents for preventing pre-eclampsia and its complications. Cochrane Database Syst Rev. 2007; (2): CD004659. doi: 10.1002/14651858.CD004659.pub2
13. Martin JA, Hamilton BE, Sutton PD, et al. Births: final data for 2007. Natl Vital Stat Rep. 2010; 58(24): 1-85.

14. Gramellini D, Fieni S, Molina E, Berretta R, Vadora E. Transvaginal sonographpic cervical length changes during normal pregnancy. $J$ Ultrasound Med. 2012; 21(3): 227-232. doi: 10.7863/jum.2002.21.3.227

15. Turner JM, Robertson NT, Hartel G, Kumar S. The impact of low-dose aspirin on adverse perinatal outcomes: a meta-analysis and metaregression. Ultrasound Obstet Gynecol. 2019. doi: 10.1002/uog.20859

16. Maclntyre DA, Sykes L, Teoh TG, Bennett PR. Prevention of preterm labor via the modulation of inflammatory pathways. J Matern Fetal Neonatal Med. 2012; 25: 17-20. doi: 10.3109/14767058.2012.666114

17. Abramovici A, Cantu J, Jenkins SM. Tocolytic therapy for acute preterm labor. Obstet Gynecol Clin North Am. 2012; 39(1): 77-87.

18. Lewis RB, Schulman JD. Influence of acetylsalicylic acid, an inhibitor of prostaglandin synthesis, on the duration of human gestation and labour. Lancet. 2009; 2(7839): 1159-1161. doi: 10.1016/s0140-6736(73)92934-6 